\title{
Effect of Controlled Substance Use Management on Prescribing Patterns and Health Outcomes Among High-Risk Users
}

\author{
Xiaoxue Chen, MPH; Qinli Ma, PhD; John Barron, PharmD; Andrea DeVries, PhD; \\ Jennifer Horn, PharmD; and Abiy Agiro, PhD
}

\begin{abstract}
BACKGROUND: The misuse of prescription drugs is a serious public health problem. Although controlled substance (CS) prescribing, in particular, opioid analgesics, has recently declined, the volume of prescriptions in 2015 was still 3 times higher than in 1999. To curb the high volume of CS prescribing, a national health plan has implemented a controlled substance utilization management (CSUM) program, a prescriber-focused educational intervention regarding patients at risk for CS misuse.
\end{abstract}

OBJECTIVE: To characterize the effect of the CSUM program on CS prescribing volumes, number of prescribers and other health outcomes (opioid overdoses, all-cause emergency department visits, and all-cause hospitalizations).

METHODS: The CSUM program identified patients who received $\geq 10 \mathrm{CS}$ prescriptions within any 3-month window for noncancer pain as being high risk for CS misuse and mailed patient medication profiles to their CS prescribers. This retrospective study was conducted on patients whose prescribers were contacted by the CSUM program from January 2014 to December 2015. The reference group included patients with carved-out pharmacy benefits who were 1:1 propensity score matched to the program group. CS prescribing volumes, number of CS prescribers, and other health care utilization measures were assessed in the 6-month pre-intervention (baseline) period and 6-month post-intervention (follow-up) period using difference-in-difference (DID) analysis.

RESULTS: After matching, each group had 17,295 patients, and there were no differences in baseline demographic and clinical characteristics. During the follow-up period, the CSUM group had 1.1 fewer prescriptions for CS (mean difference [MD] within group -3.2 vs. -2.1 prescriptions), 21 fewer days of supply (MD -27 vs. -6 days), and 0.2 fewer number of CS prescribers (MD -0.8 vs. -0.6 prescribers) per patient when compared with the reference group; all $P$ values were $<0.001$. The reductions in CS prescribing volumes and number of prescribers within the CSUM group were mainly driven by opioid analgesics, with minimal differences in benzodiazepines and stimulants between the 2 groups. The CSUM program had no significant effect on the opioid dosage strength but was associated with a lower rate of all-cause emergency department visits.

CONCLUSIONS: The CSUM program had a moderate positive effect on reducing CS prescribing volumes and number of CS prescribers compared with a reference group. Beside the focus on patients who have already received $10+$ CS prescriptions, there remains a need for more intensive approaches for accelerating targeted declines in CS in general and opioids in particular.

J Manag Care Spec Pharm. 2019;25(3):392-401

Copyright $\odot 2019$, Academy of Managed Care Pharmacy. All rights reserved.

\section{What is already known about this subject}

Abuse, misuse, and overuse of controlled substances (CS) in recent decades have been associated with increased inpatient treatment admissions for prescription drug use disorders, emergency department visits, and overdose death.

Drug use review and prescriber mailing is a light-touch approach commonly used by insurers to target inappropriate and contraindicated medication use

\section{What this study adds}

A controlled substance utilization management (CSUM) program, targeting patients who had $10+$ CS prescriptions, had a moderate positive effect on reducing prescribing volumes and number of prescribers.

Study results showed that the CSUM program has promising potential to positively affect emergency department and hospital use.

1 he misuse of prescription drugs is a serious public health problem. In 2014, the National Survey on Drug Use and Health estimated that 6.5 million Americans aged 12 years and older had misused or abused prescription controlled substances (CS) in the previous month, which represents 2.5\% of the population aged 12 years or older. ${ }^{1}$ Prescription CS were documented to be second only to marijuana as the most commonly abused drugs in the United States. ${ }^{1}$ Commonly abused prescription drug classes include stimulants used to treat attention-deficit hyperactivity disorder (ADHD), central nervous system (CNS) depressants (e.g., benzodiazepines), and opioid analgesics. ${ }^{2}$ Increased inpatient treatment admissions for prescription drug use disorders, emergency department (ED) visits, and overdose death have been attributed to the abuse, misuse, and overuse of CS in recent decades, with opioid analgesics being implicated in a majority of drug overdose fatalities. $^{3-8}$

In response to the crisis of prescription drug abuse and misuse, multilevel efforts have included an interagency strategy for responding to the prescription drug crisis from the White House, prescription drug monitoring programs (PDMPs), insurer efforts, legislation, and guidelines. ${ }^{9}$ Following these efforts, the recent decline of opioid prescriptions from 2010 to 2015 is encouraging. ${ }^{10}$ Despite the decline, the volume of 
opioid prescriptions in 2015 was still 3 times higher than in 1999, and opioid-involved overdose rates continued to increase in 2016..$^{8,10}$ These alarming facts suggest that tremendous challenges lie ahead and call for the development of evidence-based practices and interventions to combat the epidemic.

Current efforts by health insurers and pharmacy benefit manager (PBM) groups to reduce the misuse of prescribed CS include light-touch strategies such as retrospective drug utilization review (DUR) and prescriber mailings. Two recent studies, 1 conducted by a PBM (Daubresse et al., 2014) and another built on a state PDMP (Young et al., 2017), found a reduction in number of prescriptions, as well as a downward trend in number of prescribers visited per patient and number of pharmacies per patient using a pre-post case-control study design. ${ }^{11,12}$ Meanwhile, a randomized trial study initiated by another health plan (Pasquale et al., 2017) found no significant difference in reductions in opioid or pain prescription medication use and other related uses between the case and control groups. ${ }^{13}$

Current evidence regarding CS and opioid focused prescriber mailing programs has been mixed; it is unknown if the effect will continue for programs implemented at full scale. ${ }^{11-13}$ As Haegerich et al. (2014) argued, available studies measured prescribing practices rather than health outcomes (e.g., overdoses, hospitalizations, ED visits, and total health care spending). ${ }^{14}$ Anthem, a national health plan, implemented a controlled substance utilization management (CSUM) program that focused on patients with high risk of CS misuse. After identification of at-risk patients from their claims history, educational letters containing patients' prescription history were mailed to the associated prescribers.

To address the need for better evidence, our study was conducted to characterize the effect of the CSUM program. We assessed changes in prescribing patterns as well as health outcomes (opioid overdoses, all-cause ED visits, and all-cause hospitalizations) compared with a matched reference group.

\section{Methods}

\section{Data Source}

This retrospective pre-post study used administrative claims data from the HealthCore Integrated Research Environment (HIRE) from July 1, 2013, to June 30, 2016. The HIRE contains medical and pharmacy data for a large, geographically diverse population of members from 14 commercial health plans in the United States. The dataset also includes pharmacy data for pharmacy carve-out members (whose medical and pharmacy benefits are managed by separate health entities) under data use agreements. This study was conducted in full compliance with relevant provisions of the Health Insurance Portability and Accountability Act. Because researchers only used the analytic file derived from a limited dataset to perform the analyses as defined by Privacy Rule 45CFR 164.514(e), no waiver of informed consent or exemption was needed from an institutional review board

\section{Intervention: Anthem CSUM Program}

The CSUM program is an ongoing DUR and prescriber mailing program that targets patients with high risk of CS misuse and operates on a monthly basis. In each round, patients' prescription claims for CS within the previous 3 months were reviewed. The DUR targeted dispensing of opioid analgesics, benzodiazepines, stimulants, barbiturates, and sedative-hypnotic drugs from schedules II-V of the Controlled Substance Act. Patients receiving $\geq 10$ CS prescriptions within the previous 3 months were identified as high-risk CS users, and those with cancer or multiple sclerosis were excluded from the intervention. A letter was sent to each prescriber of CS medications for patients who met the program inclusion criteria. The letter provided patient medication profiles within the previous 3-month period and included information such as date dispensed, drug dispensed and strength, drug quantity, prescriber name, and pharmacy name and phone number.

\section{Study Population}

The study population consisted of high-risk CS users identified in Anthem plans from January 2014 through December 2015. The CSUM group included high-risk CS users from Anthem plans with pharmacy benefits whose prescribers had been contacted by the CSUM program; the reference group included high-risk CS users from Anthem plans with carvedout pharmacy benefits who were outside of the scope of CSUM program. Although it was possible for a patient to be identified multiple times and for multiple letters to be sent to the associated prescribers during the program evaluation period, each patient was counted only once by using the first eligible event in the analysis.

The mailing date of the letter sent to the prescriber was defined as the index date for the CSUM program group, and a date mimicking the mail date (the end of a 3-month high-risk CS user identification period +15 days) was assigned to the reference group. Members of both groups were required to be at least aged 18 years on the index date and to have continuous medical and pharmacy eligibility during the 6-month preindex and 6-month post-index periods in order to capture their drug use patterns.

\section{Outcome Measures}

The effect of the CSUM program among high-risk CS users was evaluated using a pre-post study design. Prescribing patterns and health outcomes were measured during the 6-month preindex (baseline) and 6-month post-index (program follow-up) periods. Prescribing pattern variables evaluated number of prescriptions and days of supply for CS prescriptions, number of CS prescriptions and days of supply by drug class (opioid 


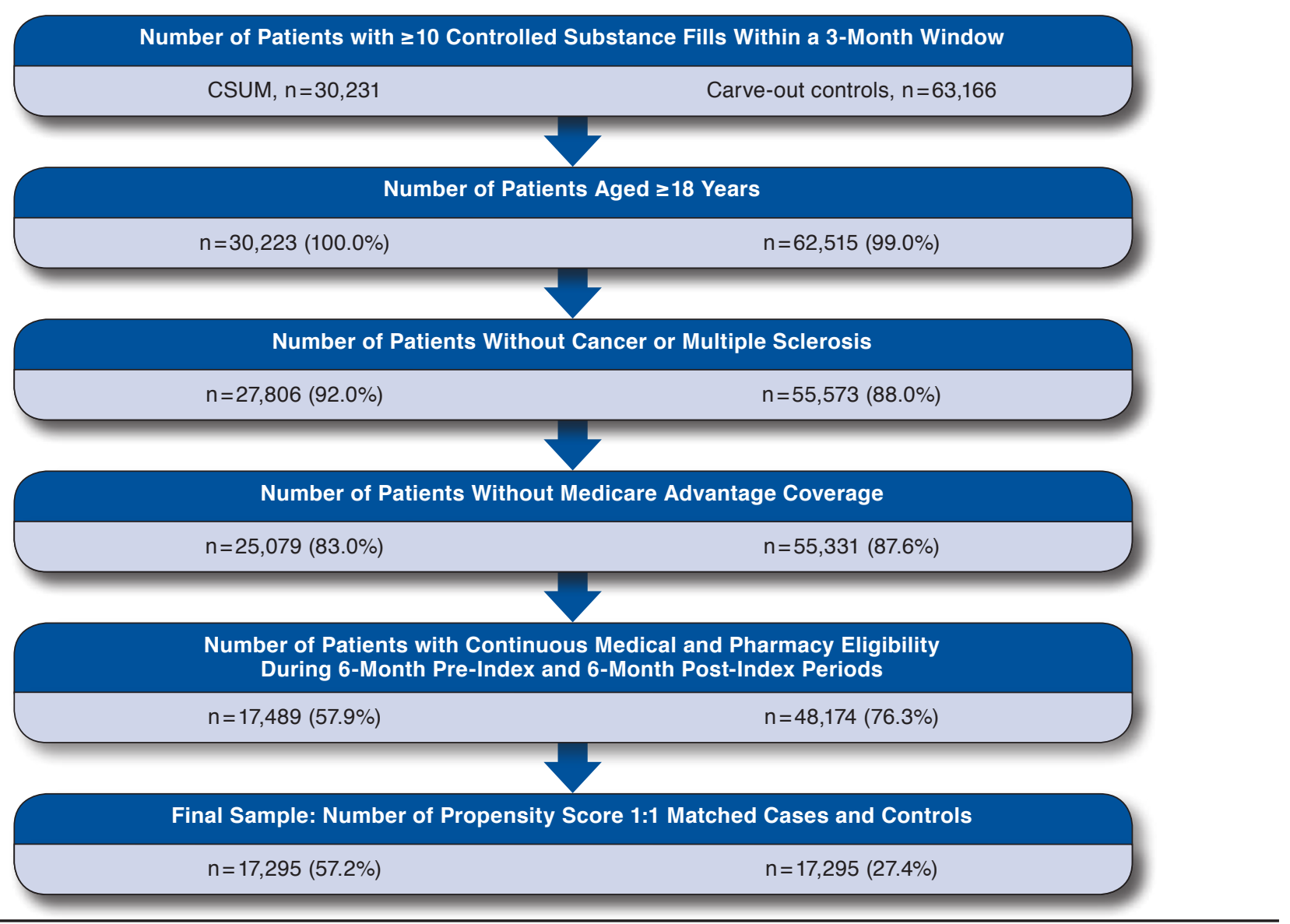

CSUM = controlled substance utilization management.

analgesics, benzodiazepines, and stimulants), number of CS prescribers per patient, as well as by drug class, and opioid dosage (as morphine milligram equivalents per day [MME]). Health outcome variables assessed rate of opioid overdose, number of all-cause ED visits, and number of all-cause hospitalizations.

\section{Covariates}

Baseline patient characteristics were measured during the 6-month pre-index period and included age; gender; geographic region; Elixhauser Comorbidity Index (ECI) score skeletal-related events (pathologic fracture, spinal cord compression, and bone surgery); psychiatric conditions (substance abuse disorder, depression, bipolar, schizophrenia and other psychotic disorders, and post-traumatic stress disorder); number of different medication classes counted through distinct Generic Product Identifier-8 (GPI-8); number of all-cause hospitalizations; number of all-cause ED visits; and all-cause medical costs.

\section{Statistical Analysis}

Descriptive statistics were generated for patient baseline characteristics and risk factors. Means and standard deviations were used to describe continuous variables; frequencies and percentages were used for categorical variables. Propensity score matching (PSM) and multivariable regression modeling were used to control for baseline differences. Combining PSM and multivariable regression modeling effectively reduces bias due to the many observed covariates and generates "double robustness" estimates. ${ }^{16,17}$ The propensity score was generated from a logistic regression model that adjusted for age, gender, geographic region, ECI score, skeletal-related events, psychiatric conditions, GPI-8 count, number of all-cause hospitalizations, and number of all-cause ED visits. The greedy nearest neighbor matching technique was used to create a 1:1 matched cohort. ${ }^{18}$ To assess the degree of balance between the 2 matched cohorts, standardized differences were calculated for the baseline characteristics post matching. A standardized difference of 0.1 or more was considered significant. 


\begin{tabular}{|c|c|c|c|}
\hline & $\begin{array}{l}\text { CSUM } \\
\text { Group }\end{array}$ & $\begin{array}{l}\text { Reference } \\
\text { Group }\end{array}$ & $\begin{array}{l}\text { Standardized } \\
\text { Difference }\end{array}$ \\
\hline Sample size, $\mathrm{n}$ & 17,295 & 17,295 & \\
\hline Age, mean years, \% (SD) & $47.2 \quad(11.5)$ & $47.2 \quad(12.4)$ & $<0.01$ \\
\hline Female, n (\%) & $10,740 \quad(62.1)$ & $10,733 \quad(62.1)$ & $<0.01$ \\
\hline Geographic region, n (\%) & & & 0.10 \\
\hline Northeast & $(12.4)$ & $(14.1)$ & \\
\hline South & $6,535 \quad(37.8)$ & $(38.7)$ & \\
\hline Midwest & $(24.6)$ & $(21.1)$ & \\
\hline West & $4,347 \quad(25.1)$ & $4,453 \quad(25.7)$ & \\
\hline Missing/unknown & $(0.1)$ & $(0.3)$ & \\
\hline \multicolumn{4}{|l|}{ Relevant conditions, n (\%) } \\
\hline Skeletal-related events ${ }^{\mathrm{a}}$ & $2,041 \quad(11.8)$ & $(11.9)$ & $<0.01$ \\
\hline Substance abuse disorder & $(19.8)$ & $(19.2)$ & 0.02 \\
\hline Depression & $(23.8)$ & $(23.7)$ & $<0.01$ \\
\hline Bipolar & $(2.6)$ & $(2.6)$ & 0.01 \\
\hline $\begin{array}{l}\text { Schizophrenia and other } \\
\text { psychotic disorders }\end{array}$ & $(1.2)$ & $(1.2)$ & $<0.01$ \\
\hline $\begin{array}{l}\text { Post-traumatic stress } \\
\text { disorder }\end{array}$ & $(2.4)$ & $(2.3)$ & 0.01 \\
\hline ECI score, mean (SD) & $2.0 \quad(2.0)$ & $(2.1)$ & -0.03 \\
\hline ECI score category, n (\%) & & & 0.02 \\
\hline 0 & $(23.1)$ & $4,054 \quad(23.4)$ & \\
\hline $1-3$ & $10,043 \quad(58.1)$ & $9,896 \quad(57.2)$ & \\
\hline $4+$ & $3,258 \quad(18.8)$ & $3,345 \quad(19.3)$ & \\
\hline $\begin{array}{l}\text { Distinct GPI-8 medication } \\
\text { count, mean (SD) }\end{array}$ & $12.1 \quad(5.8)$ & $(6.0)$ & $<0.01$ \\
\hline $\begin{array}{l}\text { Count of all-cause hospi- } \\
\text { talizations, mean (SD) }\end{array}$ & $(0.7)$ & $(0.7)$ & 0.01 \\
\hline $\begin{array}{l}\text { Count of all-cause ED } \\
\text { visits, mean (SD) }\end{array}$ & $(1.5)$ & (1.4) & 0.02 \\
\hline $\begin{array}{l}\text { All-cause medical cost, } \\
\text { mean (SD), \$ }\end{array}$ & $17,181(35,510)$ & $16,493(34,853)$ & 0.02 \\
\hline \multicolumn{4}{|c|}{$\begin{array}{l}\text { a Skeletal-related events include pathologic fracture, spinal cord compression, and } \\
\text { bone surgery. } \\
\text { CSUM = controlled substance utilization management; ECI = Elixhauser } \\
\text { Comorbidity Index; ED=emergency department; GPI-8 = Generic Product } \\
\text { Identifier-8; SD = standard deviation. }\end{array}$} \\
\hline
\end{tabular}

The effect of the CSUM program on prescribing patterns and health outcomes was assessed using difference-in-difference (DID) analysis within the matched cohorts. For longitudinal data analysis, the count outcomes were evaluated using generalized estimating equations models with log-link and Poisson distribution and random effects to control for correlations among samples; for rate of opioid overdose, the same model with logit link was used. ${ }^{19-21}$ The models included the same set of covariates that were included in the PSM. Absolute changes in DID format, and adjusted $P$ values for the interaction term of time and intervention from the models were reported. $P$ value $<0.05$ was considered statistically significant. All analyses were conducted using SAS Enterprise Guide version 7.1 (SAS Institute, Cary, NC).

\section{Results}

\section{Baseline Characteristics}

The CSUM program group had 17,489 (57.9\% of 30,231 eligible) high-risk CS users who met the study criteria; the reference group from the pharmacy carve-out population had 48,174 (76.3\% of 63,166 eligible) high-risk CS users (Figure 1). After PSM, 17,295 patients remained in each group. Baseline demographic and clinical characteristics of the matched cohorts are presented in Table 1; characteristics of the unmatched cohorts are presented in Appendix A (available in online article). Across both groups, the mean age was 47.2 years, and $62.1 \%$ of patients were female. The matched groups were also comparable in clinical characteristics; all standardized differences were $\leq 0.1$.

\section{Prescription Volumes and Number of Prescribers}

The average number of CS prescriptions was 20.5 in the CSUM group and 17.0 in the reference group during the baseline period (Table 2; median and interquartile [IQR] metrics are reported in Appendix B, available in online article). During the follow-up period, the average number of CS prescriptions decreased in both groups, and the CSUM intervention group had a larger decrease in number of CS prescriptions by 1.1 prescriptions per patient $(-3.2$ CSUM vs. -2.1 reference, $P<0.001)$. The average number of CS days of supply at baseline was 445.1 in the CSUM group and 395.0 in the reference group. Similarly, the average number of CS days of supply decreased in both groups during the follow-up period, with a larger decrease (-21.1 days per patient) seen in the CSUM group (-27.3 CSUM vs. -6.3 reference, $P<0.001)$. The average number of CS prescribers was 3.6 in the CSUM group and 3.0 in the reference group during the baseline period. Similar to the trend of CS prescribing volume, the number of CS prescribers decreased in both groups during follow-up period, with a larger decrease (-0.2 prescribers per patient) seen in the CSUM group $(-0.8$ CSUM vs. -0.6 reference, $P<0.001)$.

Changes in CS prescribing volumes and number of CS prescribers were also assessed by drug classes. Among the 3 drug classes assessed, opioids were prescribed most often $(96.1 \%$ of CSUM group and $94.3 \%$ of reference group) and had the largest drop in prescribing volumes post-intervention. The average number of opioid prescriptions per opioid user during the baseline period was 13.1 in the CSUM group and 11.3 in the reference group. The number of opioid prescriptions per opioid user decreased in both groups during the follow-up period, with a larger decrease (-1.3 prescriptions) per user in the CSUM group (-7.4 CSUM vs. -6.0 reference, $P<0.001)$. Similarly, the number of days of supply for opioid decreased in both groups during the follow-up period with a larger drop (-5.8 days) in the CSUM group $(-27.3$ CSUM and -21.5 reference, $P<0.001)$. Benzodiazepines and stimulants were prescribed less often in the study population and had minimal or almost no change in prescribing volumes post-intervention. 
Effect of Controlled Substance Use Management on Prescribing Patterns and Health Outcomes Among High-Risk Users

TABLE 2 Effect of CSUM Program on CS Prescription Volume and Number of CS Prescribers by Drug Class

\begin{tabular}{|c|c|c|c|c|c|c|c|c|}
\hline & \multicolumn{3}{|c|}{ CSUM Group n= 17,295 } & \multicolumn{3}{|c|}{ Reference Group n =17,295 } & \multirow{2}{*}{$\begin{array}{c}\text { DID } \\
\text { Absolute } \\
\text { Difference }\end{array}$} & \multirow[b]{2}{*}{$\begin{array}{l}\text { Adjusted } \\
P \text { Value }^{\mathrm{a}}\end{array}$} \\
\hline & Baseline Period & $\begin{array}{l}\text { Follow-up } \\
\text { Period }\end{array}$ & \begin{tabular}{c|} 
Absolute \\
Difference
\end{tabular} & Baseline Period & $\begin{array}{l}\text { Follow-up } \\
\text { Period }\end{array}$ & \begin{tabular}{|c|} 
Absolute \\
Difference
\end{tabular} & & \\
\hline \multicolumn{9}{|l|}{ Overall CS prescription volume } \\
\hline Prescriptions, mean (SD) & $20.5 \quad(5.5)$ & $17.3 \quad(8.3)$ & -3.2 & $17.0 \quad(5.0)$ & $14.9 \quad(7.6)$ & -2.1 & -1.1 & $<0.001$ \\
\hline Days of supply, mean (SD) & $445.1(197.7)$ & $417.8(223.2)$ & -27.3 & $395.0(214.4)$ & $388.8(281.9)$ & -6.3 & -21.1 & $<0.001$ \\
\hline \multicolumn{9}{|c|}{ CS prescription volume by drug class categories } \\
\hline \multicolumn{9}{|c|}{ Opioid analgesics } \\
\hline Users, n (\%) & 16,626 & 11,212 & $-31.3 \%$ & $16,304 \quad(94.3)$ & $10,251 \quad(59.3)$ & $-35.0 \%$ & $3.7 \%$ & 0.002 \\
\hline Prescriptions, mean (SD) & $13.1 \quad(6.2)$ & $5.8 \quad(3.4)$ & -7.4 & $11.3 \quad(5.4)$ & $5.3 \quad(3.2)$ & -6.0 & -1.3 & $<0.001$ \\
\hline Days of supply, mean (SD) & $243.0(161.9)$ & $215.7(168.4)$ & -27.3 & $225.5(171.8)$ & $204.0(203.8)$ & -21.5 & -5.8 & $<0.001$ \\
\hline \multicolumn{9}{|l|}{ Benzodiazepines } \\
\hline Users, n (\%) & 12,298 & $11,212 \quad(64.8)$ & $-6.3 \%$ & $11,300 \quad(65.3)$ & $10,251 \quad(59.3)$ & $-6.1 \%$ & $-0.2 \%$ & 0.084 \\
\hline Prescriptions, mean (SD) & $5.8 \quad(3.4)$ & $(3.4)$ & -0.1 & $5.2 \quad(3.2)$ & $5.3 \quad(3.2)$ & 0.1 & -0.1 & 0.001 \\
\hline Days of supply, mean (SD) & $141.0 \quad(90.5)$ & $147.7 \quad(89.0)$ & 6.8 & $136.3 \quad(98.3)$ & $149.4(113.8)$ & 13.1 & -6.3 & $<0.001$ \\
\hline \multicolumn{9}{|l|}{ Stimulants } \\
\hline Users, n (\%) & $4,382 \quad(25.3)$ & $4,377 \quad(25.3)$ & $0.0 \%$ & $3,737 \quad(21.6)$ & $3,651 \quad(21.1)$ & $-0.5 \%$ & $0.5 \%$ & 0.005 \\
\hline Prescriptions, mean (SD) & $7.1 \quad(4.0)$ & $6.8 \quad(3.9)$ & -0.2 & $6.5 \quad(3.7)$ & $6.4 \quad(3.9)$ & -0.1 & -0.1 & 0.204 \\
\hline Days of supply, mean (SD) & $207.9(112.0)$ & $204.3(112.1)$ & -3.6 & $202.3(123.5)$ & $203.6(135.7)$ & 1.3 & -4.9 & 0.114 \\
\hline CS prescribers, mean (SD) & $3.6 \quad(2.2)$ & $2.8 \quad(2.0)$ & -0.8 & $3.0 \quad(2.0)$ & $2.4 \quad(1.8)$ & -0.6 & -0.2 & $<0.001$ \\
\hline \multicolumn{9}{|c|}{ CS prescribers by drug class categories } \\
\hline Opioid analgesics, mean (SD) & $(2.1)$ & $(1.8)$ & -0.8 & (1.9) & $(1.7)$ & -0.6 & -0.2 & $<0.001$ \\
\hline Benzodiazepines, mean (SD) & $(1.0)$ & $(0.9)$ & -0.2 & $(0.9)$ & $(0.8)$ & -0.1 & -0.1 & 0.047 \\
\hline Stimulants, mean (SD) & $0.4 \quad(0.7)$ & $0.3 \quad(0.7)$ & 0.0 & $(0.6)$ & $0.3 \quad(0.6)$ & 0.0 & 0.0 & 0.131 \\
\hline Opioid dosage MME, mean (SD) & $64.4 \quad(77.4)$ & $67.4 \quad(83.2)$ & 3.0 & $59.7 \quad(67.7)$ & $61.9 \quad(71.2)$ & 2.2 & 0.8 & 0.599 \\
\hline
\end{tabular}

Parallel to the trend of CS prescription volumes, the decrease in number of CS prescribers mainly came from the opioid class with some contribution from benzodiazepines (DID for opioid, -0.2, $P<0.001$; DID for benzodiazepine, -0.05, $P=0.047$; DID for stimulant, -0.01, $P=0.131$; Table 2). Average opioid dosage strength during the baseline period was 64.4 MME in the CSUM group and 59.7 MME in the reference group. Despite the changes in prescription volume and number of prescribers, there was no statistically significant change in opioid dosage strength within the CSUM group in the follow-up period (DID for MME daily dosing, $0.8 ; P=0.599$ ).

\section{Other Health Outcomes}

The rate of opioid overdose at baseline was $4.8 \%$ in the CSUM group and $4.7 \%$ in the reference. Although the rate of opioid overdose increased in both groups in the follow-up period, the increase was not significantly larger within the CSUM group (1.2\% CSUM vs. $0.8 \%$ reference group; DID, $0.3 \% ; P=0.234$; Table 3). A larger decrease in number of ED visits (by 27.1 visits per 1,000 patients) was seen during the follow-up period in the CSUM group (-141 per 1,000 patients CSUM vs. -114 per 1,000 patients reference, $P=0.003$ ). Number of hospitalizations decreased in both groups during the follow-up period, and the magnitude of decrease was similar (-97 per 1,000 patients CSUM vs. -82 per 1,000 patients reference, $P=0.065$ ).

\section{Discussion}

This study characterized the effect of the CSUM program, a DUR and prescriber mailing program, on CS prescribing patterns and other health outcomes among patients with high risk of CS misuse. The CSUM program is a simple and inexpensive approach that sends letters with patient medication profiles to their prescribers and operates on a monthly basis. The CSUM program was associated with a moderate decrease in number of CS prescriptions and number of CS prescribers following the intervention when compared with a PSM reference group. Further analysis by drug classes showed that the largest decrease in CS prescription patterns and number of CS prescribers came from the use of opioid analgesics. This study also assessed the downstream effect of the CSUM program on opioid overdose, all-cause ED visits, and all-cause hospitalizations. Although the CSUM program did not positively effect opioid overdose rates, it was associated with a larger decrease in ED visits in the follow-up period. Besides the clinical benefits, the CSUM program yielded net savings, given the low program implementation cost. The reduction in number of CS dispensed led to a direct 
TABLE 3 Effect of CSUM Program on Other Health Outcomes

\begin{tabular}{|c|c|c|c|c|c|c|c|c|}
\hline \multirow[b]{3}{*}{ Opioid overdose, n (\%) } & \multicolumn{3}{|c|}{ CSUM Group n= 17,295 } & \multicolumn{3}{|c|}{ Reference Group n = 17,295 } & \multirow[b]{2}{*}{$\begin{array}{c}\text { DID Absolute } \\
\text { Difference }\end{array}$} & \multirow[b]{2}{*}{$\begin{array}{l}\text { Adjusted } \\
P \text { Value }^{\mathrm{a}}\end{array}$} \\
\hline & $\begin{array}{l}\text { Baseline } \\
\text { Period }\end{array}$ & $\begin{array}{l}\text { Follow-up } \\
\text { Period }\end{array}$ & $\begin{array}{l}\text { Absolute } \\
\text { Difference }\end{array}$ & $\begin{array}{l}\text { Baseline } \\
\text { Period }\end{array}$ & $\begin{array}{l}\text { Follow-up } \\
\text { Period }\end{array}$ & $\begin{array}{l}\text { Absolute } \\
\text { Difference }\end{array}$ & & \\
\hline & $822 \quad(4.8)$ & $1,025 \quad(5.9)$ & $1.2 \%$ & $818 \quad(4.7)$ & $961 \quad(5.6)$ & $0.8 \%$ & $0.3 \%$ & 0.234 \\
\hline $\begin{array}{l}\text { Hospitalizations per } 1,000 \text { patients, } \\
\text { mean (SD) }\end{array}$ & $286 \quad(701)$ & $189 \quad(630)$ & -97 & $279 \quad(712)$ & $197 \quad(639)$ & -82 & -15.0 & 0.065 \\
\hline $\begin{array}{l}\text { ED visits per } 1,000 \text { patients, } \\
\text { mean (SD) }\end{array}$ & $622(1,463)$ & $481(1,367)$ & -141 & $597(1,431)$ & $483(1,446)$ & -114 & -27.1 & 0.003 \\
\hline
\end{tabular}

aAdjusted P values for the interaction term of intervention and time were outputted from generalized estimating equation models.

CSUM = controlled substance utilization management; DID =difference in difference; SD =standard deviation.

plan saving of $\$ 38.2$ per high-risk CS user, and potentially more savings accrued from reduced ED visits and other health services.

Whereas the effect of the CSUM program on CS prescription volume and CS prescribers mostly came from usage of opioid analgesics, the effect on the rate of opioid overdose was minimal and not statistically significant. Notably, the rate of opioid overdose increased during the follow-up period in both groups. This finding likely reflected the increased recognition of the issue by providers or escalation of the ongoing national opioid epidemic (e.g., illicit use of opioids or heroin due to lack of access-a result of more stringent restrictions on opioid prescribing), as opioid-related mortality continued to grow during the study period. ${ }^{8,22,23}$ The increasing rate of opioid overdose seen in our study speaks to the need for future efforts specifically designed to affect the use of opioid analgesics.

Our study findings support the use of DUR and prescriber mailing interventions. DUR and prescriber mailing is an approach commonly used by insurers to target use of inappropriate and contraindicated medication. Such programs often report moderate to substantial success in decreasing unsafe medication use, but the evidence base is limited in rigor, since the use of a control group has frequently been lacking in published study designs. ${ }^{24,25}$

Three DUR evaluation studies that focused on high-risk controlled substance and opioid users have been published recently. ${ }^{11-13}$ These studies used either a control group or randomized study design to generate more robust results; however, they have produced mixed results. Daubresse et al. constructed a composite CS risk score based on CS prescription claims and number of prescribers/pharmacies. ${ }^{11}$ Intervention letters were sent to prescribers of patients with a high CS risk score $(\geq 12)$ and 12 or more CS prescription claims within the 3-month pre-intervention period. ${ }^{11}$ This DUR intervention study found that claims for CS decreased by an average of 1 claim during the 6-month post-intervention period, a similar magnitude of program effect as seen in our study, with a nonstatistically significant reduction in number of prescribers and pharmacies compared with a reference group. ${ }^{11}$ Young et al. used a matched case-control study that identified patients from a state PDMP who had multiple provider episodes (also referred to as doctor/pharmacy shopping) and intervened by sending prescribers a letter detailing the patient's 12 -month prescription history. ${ }^{12}$ The authors found statistically significant reductions in prescribing metrics (number of prescriptions, number of prescribers, opioid dosing, and MME). ${ }^{12}$ A 4-arm randomized trial conducted by Pasquale et al. evaluated a health plan program that targeted potential opioid use disorder and found similar magnitude of reductions in opioid use patterns between the case and control groups, which inferred no effect from the program. ${ }^{13}$ As the program effect of such a simple approach seems to be moderate based on our study and previous CS/opioid studies, the effect of the Pasquale et al. intervention could have been overshadowed by the downward trend of opioid prescription volumes observed during the same time period. ${ }^{10}$ However, our study was empowered to detect moderate effect, given a much larger sample size. We also found that the moderate effect of the program held after the program was scaled up.

Evidence of the effect of CS/opioid utilization management programs on downstream health outcomes is limited. A search of available literature found 1 study that indirectly measured the association of the CS score algorithm with health care costs and hospitalizations. ${ }^{26}$ Starner et al. (2016) found that all-cause hospitalizations changed $0.9 \%$ and ED visits changed $1.5 \%$ for each 1-point CS score change. ${ }^{26}$ The Daubresse et al. prescriber letter campaign that targeted prescribers of individuals with a CS score $\geq 12$ used the same CS algorithm and was associated with a 1.36 point reduction in CS score. ${ }^{11}$ Applying the hospital use findings of the Starner et al. study to the CS score reduction of the Daubresse et al. study could translate into a $1.2 \%$ reduction in hospitalizations and $2.0 \%$ reduction in ED visits. ${ }^{11,26}$ Notably, our study design allowed for direct measurement of these downstream outcomes and found similar results to Daubresse et al. combined with Starner et al., confirming the positive health care resource use effect of the program..$^{11,26}$

Although the patient identification criteria in our study are not directly tied to documented or self-reported CS misuse, the criteria intend to identify patients with increased risk of misuse due to CS overuse. Our criteria focused on CS prescription 
volumes over a certain period of time. The incorporation of both medical and pharmacy claims review in the CSUM program allows the ability to tease apart patients with cancer or multiple sclerosis, many of whom need CS to relieve their symptoms. With a recent call from the U.S. government to decrease the prescribing of opioids by one third in the next 3 years, the ability to identify and exclude patients with cancer from such interventions will remain important. ${ }^{27}$ There has been a high degree of variability in patient identification criteria in drug utilization management programs focusing on either CS in general or, more specifically, on opioids. ${ }^{28} \mathrm{~A}$ thorough comparison of different patient identification criteria is currently lacking and warrants further research to inform program design.

\section{Implications}

The CSUM, a DUR and prescriber mailing program, had a moderate positive effect on overall CS prescribing patterns and some promising effect on overall health care outcomes. To combat the persistent high CS prescription volumes and the ongoing opioid crisis, there is a significant need for integrated approaches and better coordination of current initiatives. Among multistakeholder efforts, insurers can play an important role in combating CS overuse by undertaking multidimensional approaches throughout the patient CS use journey (e.g., prevention, education, and minimizing early exposure) and by working collectively with prescribers. ${ }^{29}$

In recent years, there have been many other approaches of DUR programs undertaken by insurers that showed great promise, such as intervention on high-dose opioid and opioid and CNS combination therapy, short-acting opioid quantity limit, and opioid tapering programs for conditions of the back and spine. ${ }^{24,30,31}$ Assessment of the synergy of combined interventions and evaluation of the effect on health outcomes of these utilization management programs are needed to enrich the knowledge base of such programs, maximize program utility, and ultimately optimize resource allocations.

\section{Limitations}

As of June 2013, 47 states have operational PDMPs, which enabled providers and pharmacists to access a patient's recent pattern of CS use or misuse. ${ }^{32}$ A majority of state PDMPs are authorized to send unsolicited reports to providers when prescriber or prescription recipient activity exceeds certain thresholds. ${ }^{33}$ It is possible that state PDMP activity or provider use of the PDMP databases during the study period may have affected CS use in both groups. Both groups had large reductions in many of the outcome measures during the follow-up period, possibly due to regression to the mean or other initiatives underway to combat CS/opioid misuse.
The CSUM program does not track whether prescribers received or read the letter, therefore we were unable to quantify this aspect. CS medications purchased at retail pharmacies with cash were not captured within the claims data environment, which could potentially affect the intervention effect. ${ }^{34}$ The reference group, consisting of a third-party carve-out population, could be subject to other CSUM-like programs that were unknown to the researchers and could cause the program effect to be underestimated.

The number of CS prescriptions being used for patient identification criteria (exposure) and an outcome measure limits the ability to use time-series analysis. Instead, the study applied a pre-post design to assess the effect of the CSUM program. The program effect on CS medication costs and total pharmacy costs could not be evaluated, since pharmacy cost information was not available for carve-out pharmacy data in the reference group. Although our algorithm of identifying high-risk CS users was developed with great care, it was developed empirically and needs further validation.

\section{Conclusions}

Prescriber-focused educational mailing had a moderate positive effect on reducing prescribing volumes and number of prescribers. The CSUM program, a simple and inexpensive approach, is used by insurers to tackle CS overuse collaboratively with prescribers. Although the program carries promising potential to positively affect ED and hospital use, more integrated approaches and better coordination of current initiatives are needed to combat the ongoing epidemic. Besides the focus on patients who have already received 10 or more CS prescriptions, there remains a need for more intensive approaches for accelerating targeted declines in CS in general and opioids in particular.

\section{Authors}

XIAOXUE CHEN, MPH; QINLI MA, PhD; JOHN BARRON, PharmD; ANDREA DEVRIES, PhD; and ABIY AGIRO, PhD, HealthCore, Wilmington, Delaware. JENNIFER HORN, PharmD, Anthem, Indianapolis, Indiana.

AUTHOR CORRESPONDENCE: Xiaoxue Chen, MPH, HealthCore, 123 Justison St., Ste. 200, Wilmington, DE 19801. Tel.: 302.230.2090; E-mail: xchen@healthcore.com.

\section{DISCLOSURES}

Funding for this study was provided by Anthem, which had no role in study design, data interpretation, manuscript development, or the decision to publish. Chen, Ma, Barron, DeVries, and Agiro are employees of HealthCore, a wholly owned subsidiary of Anthem. Horn is an employee of Anthem. 


\section{REFERENCES}

1. Center for Behavioral Health Statistics and Quality. Behavioral health trends in the United States: results from the 2014 National Survey on Drug Use and Health. Health and Human Services Publication No. SMA 15-4927, NSDUH Series H-50. September 2015. Available at: https://www.samhsa. gov/data/sites/default/files/NSDUH-FRR1-2014/NSDUH-FRR1-2014.pdf. Accessed January 29, 2019.

2. National Institute on Drug Abuse. Prescription drug abuse. National Institute of Health Publication Number 11-4881. Revised October 2011. Available at: https://www.drugabuse.gov/sites/default/files/rxreportfinalprint. pdf. Accessed January 29, 2019.

3. Jones CM, McAninch JK. Emergency department visits and overdose deaths from combined use of opioids and benzodiazepines. Am J Prev Med. 2015;49(4):493-501.

4. National Institute on Drug Abuse. Misuse of prescription drugs. Updated December 2018. Available at: https://www.drugabuse.gov/publications/ research-reports/misuse-prescription-drugs. Accessed January 29, 2019.

5. Rudd RA, Seth P, David F, Scholl L. Increases in drug and opioid-involved overdose deaths-United States, 2010-2015. MMWR Morb Mortal Wkly Rep. 2016;65(5051):1445-52.

6. Substance Abuse and Mental Health Services Administration. Drug abuse warning network, 2011: national estimates of drug-related emergency department visits. HHS Publication No. (SMA) 13-4760. May 2013. Available at: https://www.samhsa.gov/data/sites/default/files/DAWN2kllED/ DAWN2k11ED/DAWN2k11ED.pdf. Accessed January 29, 2019.

7. Substance Abuse and Mental Health Services Administration. Treatment episode data set (TEDS): 2003-2013. National admissions to substance abuse treatment services. HHS Publication No. (SMA) 15-4934. December 2015. Available at: https://www.samhsa.gov/data/sites/default/files/2003_2013_ TEDS_National/2003_2013_Treatment_Episode_Data_Set_National.pdf. Accessed January 29, 2019.

8. Centers for Disease Control and Prevention. Opioid overdose: understanding the epidemic. Updated December 18, 2018. Available at: https://www.cdc. gov/drugoverdose/epidemic/index.html. Accessed January 29, 2019.

9. National Institute on Drug Abuse. Prescription opioids and heroin January 2018. Available at: https://d14rmgtrwzf5a.cloudfront.net/sites/ default/files/19774-prescription-opioids-and-heroin_0.pdf. Accessed January 29, 2019

10. Guy GP Jr, Zhang K, Bohm MK, et al. Vital signs: changes in opioid prescribing in the United States, 2006-2015. MMWR Morb Mortal Wkly Rep. 2017;66(26):697-704

11. Daubresse M, Gleason PP, Peng Y, Shah ND, Ritter ST, Alexander GC. Impact of a drug utilization review program on high-risk use of prescription controlled substances. Pharmacoepidemiol Drug Saf. 2014;23(4):419-27.

12. Young LD, Kreiner PW, Panas L. Unsolicited reporting to prescribers of opioid analgesics by a state prescription drug monitoring program: an observational study with matched comparison group. Pain Med. 2018;19(7):1396-407.

13. Pasquale MK, Sheer RL, Mardekian J, et al. Educational intervention for physicians to address the risk of opioid abuse. J Opioid Manag. 2017;13(5):303-13

14. Haegerich TM, Paulozzi LJ, Manns BJ, Jones CM. What we know, and don't know, about the impact of state policy and systems-level interventions on prescription drug overdose. Drug Alcohol Depend. 2014;145:34-47.

15. Elixhauser A, Steiner C, Harris DR, Coffey RM. Comorbidity measures for use with administrative data. Med Care. 1998;36(1):8-27.

16. Rubin DB, Thomas N. Combining propensity score matching with additional adjustments for prognostic covariates. J Am Stat Assoc. 2000;95(450):573-85.

17. Stuart EA. Matching methods for causal inference: a review and a look forward. Stat Sci. 2010;25(1):1-21.
18. Parsons LS. Reducing bias in a propensity score matched-pair sample using greedy matching techniques. Paper presented at: Twenty-sixth Annual SAS Users Group International Conference; April 22-25, 2011; Long Beach, CA. Available at: https://support.sas.com/resources/papers/proceedings/proceedings/sugi26/p214-26.pdf. Accessed January 29, 2019.

19. Diggle PJ, Heagerty PJ, Liang KY, Zeger SL. In: Analysis of Longitudinal Data. 2nd ed. Oxford, UK: Oxford University Press; 2002.

20. Dunlop DD. Regression for longitudinal data: a bridge from least squares regression. Am Stat. 1994:48(4):299-303.

21. Zeger SL, Liang KY. Longitudinal data analysis for discrete and continuous outcomes. Biometrics. 1986;42(1):121-30.

22. Ruhm CJ. Geographic variation in opioid and heroin involved drug poisoning mortality rates. Am J Prev Med. 2017;53(6):745-53.

23. Ingraham C. CDC releases grim new opioid overdose figures: 'we're talking about more than an exponential increase'. Washington Post. December 21, 2017. Available at: https://www.washingtonpost.com/news/wonk/ $\mathrm{wp} / 2017 / 12 / 21 /$ cdc-releases-grim-new-opioid-overdose-figures-were-talking-about-more-than-an-exponential-increase/?utm_term=.28c285bbda77. Accessed January 29, 2019.

24. Qureshi N, Wesolowicz LA, Liu CM, Tungol Lin A. Effectiveness of a retrospective drug utilization review on potentially unsafe opioid and central nervous system combination therapy. J Manag Care Spec Pharm. 2015;21(10):938-44. Available at: https://www.jmcp.org/doi/10.18553/ jmcp.2015.21.10.938.

25. Shoemaker SJ, Pozniak A, Subramanian R, Mauch D. Effect of 6 managed care pharmacy tools: a review of the literature. J Manag Care Pharm. 2010;16(6 Suppl):S3-20. Available at: http://www.amcp.org/data/jmcp/ JulSuppA.pdf.

26. Starner CI, Qiu Y, Karaca-Mandic P, Gleason PP. Association of a controlled substance scoring algorithm with health care costs and hospitalizations: a cohort study. J Manag Care Spec Pharm. 2016;22(12):1403-10. Available at: https://www.jmcp.org/doi/10.18553/jmcp.2016.22.12.1403.

27. American Society of Clinical Oncology. Administration announces opioid plan; ASCO submits comments to FDA Steering Committee [press release]. April 23, 2018. Available at: https://www.asco.org/advocacy-policy/ asco-in-action/administration-announces-opioid-plan-asco-submits-comments-fda. Accessed January 29, 2019.

28. Roberts AW, Skinner AC. Assessing the present state and potential of Medicaid controlled substance lock-in programs. J Manag Care Spec Pharm. 2014;20(5):439-46c. Available at: https://www.jmcp.org/doi/10.18553/ jmcp.2014.20.5.439

29. Optum. Opioid epidemic: deflecting the curve. 2019. Available at: https://www.optum.com/resources/library/deflecting-the-curve.html. Accessed January 29, 2019.

30. Page J, Traver R, Patel S, Saliba C. Implementation of a proactive pilot health plan-driven opioid tapering program to decrease chronic opioid use for conditions of the back and spine in a Medicaid population. J Manag Care Spec Pharm. 2018;24(3):191-96. Available at: https://www.jmcp.org/ doi/10.18553/jmcp.2018.24.3.191.

31. Riggs CS, Billups SJ, Flores S, Patel RJ, Heilmann RMF, Milchak JL. Opioid use for pain management after implementation of a Medicaid shortacting opioid quantity limit. J Manag Care Spec Pharm. 2017;23(3):346-54 Available at: https://www.jmcp.org/doi/10.18553/jmcp.2017.23.3.346.

32. Department of Health and Human Services. Prescription drug monitoring program interoperability standards: a report to Congress. September 2013. Available at: https://www.healthit.gov/sites/default/files/fdasiall4lreport_final.pdf. Accessed January 29, 2019.

33. Substance Abuse and Mental Health Services Administration. In brief: prescription drug monitoring programs: a guide for healthcare providers. HHS Publication No. (SMA) 16-4997. 2017. Available at: https://store.samhsa.gov/system/files/sma16-4997.pdf. Accessed January 29, 2019.

34. Hartung DM, Ahmed SM, Middleton L, et al. Using prescription monitoring program data to characterize out-of-pocket payments for opioid prescriptions in a state Medicaid program. Pharmacoepidemiol Drug Saf. 2017;26(9):1053-60. 
APPENDIX A Baseline Demographic and Clinical Characteristics for Patients Meeting CSUM Program Criteria: Before Matching

\begin{tabular}{|c|c|c|c|c|c|}
\hline & \multicolumn{2}{|c|}{ CSUM Group } & \multicolumn{2}{|c|}{ Reference Group } & Standardized Difference \\
\hline Sample size, $\mathrm{n}$ & \multicolumn{2}{|c|}{17,489} & \multicolumn{2}{|c|}{48,174} & \\
\hline Age, mean years, \% (SD) & 47.0 & (11.5) & 49.5 & (12.9) & -0.20 \\
\hline Female, n (\%) & 10,874 & $(62.2)$ & 30,180 & $(62.6)$ & -0.01 \\
\hline Geographic region, n (\%) & & & & & 0.14 \\
\hline Northeast & 2,180 & $(12.5)$ & 6,210 & $(12.9)$ & \\
\hline South & 6,597 & $(37.7)$ & 18,986 & $(39.4)$ & \\
\hline Midwest & 4,314 & $(24.7)$ & 9,282 & $(19.3)$ & \\
\hline West & 4,384 & $(25.1)$ & 13,587 & $(28.2)$ & \\
\hline Missing/unknown & 14 & $(0.1)$ & 109 & $(0.2)$ & \\
\hline \multicolumn{6}{|l|}{ Relevant conditions, n (\%) } \\
\hline Skeletal-related events ${ }^{\mathrm{a}}$ & 2,124 & $(12.1)$ & 4,946 & $(10.3)$ & 0.06 \\
\hline Substance abuse disorder & 3,584 & $(20.5)$ & 7,752 & $(16.1)$ & 0.11 \\
\hline Depression & 4,217 & $(24.1)$ & 10,550 & (21.9) & 0.05 \\
\hline Bipolar & 478 & $(2.7)$ & 1,137 & $(2.4)$ & 0.02 \\
\hline Schizophrenia and other psychotic disorders & 216 & $(1.2)$ & 516 & $(1.1)$ & 0.02 \\
\hline Post-traumatic stress disorder & 440 & $(2.5)$ & 1,006 & $(2.1)$ & 0.03 \\
\hline ECI score, mean (SD) & 2.1 & $(2.0)$ & 2.2 & $(2.1)$ & -0.07 \\
\hline ECI score category, n (\%) & & & & & 0.06 \\
\hline 0 & 4,023 & $(23.0)$ & 10,729 & $(22.3)$ & \\
\hline $1-3$ & 10,141 & $(58.0)$ & 27,093 & $(56.2)$ & \\
\hline $4+$ & 3,325 & $(19.0)$ & 10,352 & $(21.5)$ & \\
\hline Distinct GPI-8 medication count, mean (SD) & 12.2 & $(5.9)$ & 12.0 & $(5.9)$ & 0.04 \\
\hline Count of all-cause hospitalizations, mean (SD) & 0.3 & $(0.7)$ & 0.3 & $(0.7)$ & 0.01 \\
\hline Count of all-cause ED visits, mean(SD) & 0.7 & $(1.7)$ & 0.54 & $(1.4)$ & 0.09 \\
\hline All-cause medical cost, mean (SD), \$ & 17,538 & $(36,201)$ & 16,004 & $(49,925)$ & 0.04 \\
\hline
\end{tabular}

aSkeletal-related events include pathologic fracture, spinal cord compression, and bone surgery.

CSUM = controlled substance utilization management; ECI = Elixhauser Comorbidity Index; ED = emergency department; GPI-8=Generic Product Identifier-8;

$S D=$ standard deviation . 


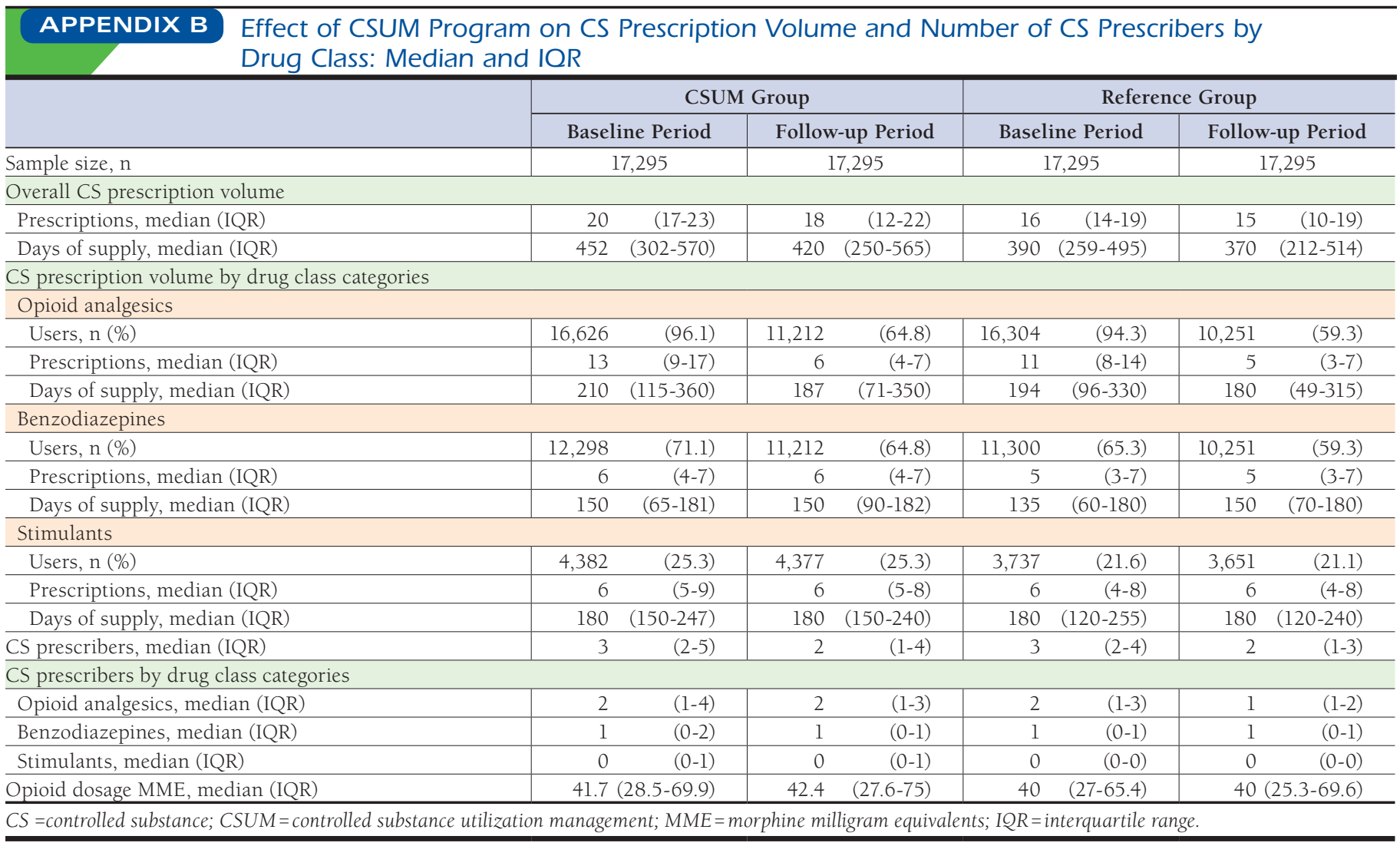

